\title{
Does Scheduling a Postdischarge Visit with a Primary Care Physician Increase Rates of Follow-up and Decrease Readmissions?
}

\author{
Felippe $\bigcirc$ Marcondes, MD1, Paawan Punjabi, MD2, Lauren Doctoroff, MD ${ }^{3,4}$, Anjala Tess, MD ${ }^{3,4}$, \\ Sarah $\mathrm{O}^{\prime}$ Neill, $\mathrm{MBA}^{4}$, Timothy Layton, $\mathrm{PhD}^{3}$, Kramer Quist, BS ${ }^{3}$, Ateev Mehrotra, MD, MPH ${ }^{3,4 *}$
}

${ }^{1}$ University of Texas Medical Branch, Galveston, Texas; ${ }^{2}$ New York University School of Medicine, New York, New York; ${ }^{3}$ Harvard Medical School, Boston, Massachusetts; ${ }^{4}$ Beth Israel Deaconess Medical Center, Boston, Massachusetts.

BACKGROUND: Driven in part by Medicare's Hospital Readmissions Reduction Program, hospitals are focusing on improving the transition from inpatient to outpatient care with particular emphasis on early follow-up with a primary care physician (PCP).

OBJECTIVE: To assess whether the implementation of a scheduling assistance program changes rates of PCP follow-up or readmissions.

DESIGN: Retrospective cohort study.

SETTING: An urban tertiary care center

PATIENTS: A total of 20,918 adult patients hospitalized and discharged home between September 2008 and October 2015.

INTERVENTION: A postdischarge appointment service to facilitate early PCP follow-up.

MAIN MEASURES: Primary outcomes were rates of follow-up visits with a PCP within seven days of discharge and hospital readmission within 30 days of discharge. Our first analysis assessed differences in outcomes among patients with and without the use of the service. In a second analysis, we exploited the fact that the service was not available on weekends and conducted an instrumental variable analysis that used the interaction between the intervention and day of the week of admission.

RESULTS: In our multivariable analysis, use of the appointment service was associated with much higher rates of PCP follow-up (+31.9 percentage points, 95\% $\mathrm{Cl}: 30.2,33.6 ; P<.01)$ and a decrease in readmission $(-3.8$ percentage points, $95 \% \mathrm{Cl}:-5.2,-2.4 ; P<.01)$. In the instrumental variable analysis, use of the service also increased the likelihood of a PCP follow-up visit (33.4 percentage points, 95\% Cl: 7.9, 58.9; $P=.01$ ) but had no significant impact on readmissions $(-2.5$ percentage points, 95\% Cl: $-22.0,17.0 ; P=.80)$.

CONCLUSIONS: The postdischarge appointment service resulted in a substantial increase in timely PCP followup, but its impact on the readmission rate was less clear. Journal of Hospital Medicine 2019;14:e37-e42. (C) 2019 Society of Hospital Medicine

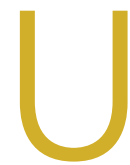

nder the Hospital Readmission Reduction Program (HRRP), hospitals with higher than expected readmissions for select conditions receive a financial penalty. In 2017, hospitals were penalized a total of $\$ 528$ million. ${ }^{1,2}$ In an effort to deter readmissions, hospitals have focused on the transition from inpatient to outpatient care with particular emphasis on timely follow-up with a primary care physician (PCP). ${ }^{3-7}$ Medicare has also introduced transitional care codes, which reimburse physicians for follow-up care after a hospitalization.

Most observational studies have found an association among patients discharged from the hospital between early follow-up with a PCP and fewer readmissions. One study found that patients without timely PCP follow-up after hospitalization on medical wards had a 10-fold increase in the likelihood of

*Corresponding Author: Ateev Mehrotra, MD, MPH; E-mail: Mehrotra@hcp. med.harvard.edu; Telephone: 617-432-3905.

Find Additional Supporting Information in the online version of this article.

Received: April 15, 2019; Revised: July 29, 2019; Accepted: August 15, 2019

(C) 2019 Society of Hospital Medicine DOI 10.12788/jhm.3309 readmission. ${ }^{5}$ This association between early PCP follow-up and readmissions has been echoed in studies of all general admissions, ${ }^{5}$ as well as hospitalizations specific to heart failure, ${ }^{7,8}$ chronic obstructive pulmonary disease, ${ }^{3}$ high-risk surgery, ${ }^{9}$ and sickle cell disease. ${ }^{10}$ One potential concern with this prior literature is that unmeasured patient characteristics might be confounders; for example, patients with more social support may be both more likely to have follow-up visits and less likely to have readmissions. Also, there are several studies showing no association between early PCP appointments and readmission rates. ${ }^{6,9,11-13}$

Several prior interventional studies to improve the care transition from hospital to outpatient care have successfully deterred readmissions. ${ }^{14}$ In these trials, facilitating early PCP follow-up is just one component of a larger intervention, ${ }^{15}$ and a systemic review noted that the interventions were heterogeneous and often consisted of multiple complex steps. ${ }^{6}$ It is less clear whether interventions to facilitate early PCP follow-up alone are successful.

In this study, we evaluated the impact of an intervention that focused on facilitating early follow-up of PCPs. We assessed the impact of this intervention on the likelihood of having a 
PCP appointment within seven days of discharge and being readmitted within 30 days of discharge.

\section{METHODS}

\section{Postdischarge Appointment Service}

In the fall of 2009, Beth Israel Deaconess introduced a postdischarge appointment intervention to facilitate follow-up with PCPs and specialty physicians after discharge from the hospital. Within the provider order entry system, attending and resident physicians enter a discharge appointment request for specified providers within and outside of the medical center and a specified time period. For example, a physician may enter a request to schedule a PCP appointment within 2-3, 4-8, 9-15, 16-30, or $>30$ days of discharge. Physicians are asked to submit this request on the day of discharge. The request is transmitted to dedicated staff (four full-time administrative staff and four part-time registered nurses) who verify the PCP, process the orders, and call the relevant practices to book the appointments. The date and time of the follow-up appointments are set without input from the patient. The details of the appointment, location, phone number of the clinic, and any other relevant instructions are automatically entered into the discharge instructions and discharge summary. The service is available Monday through Friday, and the turnaround on appointment creation is typically within one to three hours of the request. For patients who do not have a PCP or want to switch their $\mathrm{PCP}$, the discharging physician can request a new PCP within the health system, and the service will schedule an appointment in this new PCP's practice. Anecdotally, physicians are more likely to order the postdischarge appointment service for patients with more complex illnesses and longer lengths of stay and for those who come from underserved populations, as they perceive that it is more important for the patient to have this follow-up appointment, and/or the patient may have a harder time navigating the system and scheduling an appointment. Because of funding limitations, the hospital limited the intervention to hospitalizations on the general medicine and cardiology services. It was expanded in late 2011 to include the trauma surgery service.

\section{Study Population}

We conducted a retrospective, cohort study at Beth Israel Deaconess Medical Center, a tertiary care hospital, using data derived from electronic health records for all hospitalizations from September 2008 to October 2015. At this medical center, the vast majority of patients on the general medicine service are cared for by hospitalists and not their PCPs. We focused on patients 18 years of age or older discharged home and excluded hospitalizations where the patient died, was transferred to another hospital, or was discharged to a skilled nursing facility or inpatient rehabilitation hospital. We excluded patients who were kept under observation in the emergency department (ED), but our data did include patients cared for on a hospital ward under observation. To measure whether patients attended a follow-up visit, we used internal scheduling data and therefore only included hospitalizations for patients with a
PCP affiliated with the Beth Israel Deaconess medical system. This includes patients previously without a PCP whose first PCP appointment was after discharge. Finally, we limited our sample to hospitalizations on the general medicine and cardiology services because, as previously discussed, these are the services where the intervention was available. To address transfers within the hospital from one service to another, we categorized hospitalizations by the service on the date of discharge.

\section{Outcomes}

The primary outcomes of this study were kept PCP follow-up visits within seven days and readmission within 30 days of discharge. We focused on PCP visits within seven days, as this has been the measure used in prior research, 5,7 but conducted a sensitivity analysis of PCP follow-up within 14 days. No-shows for the scheduled follow-up PCP appointments were not included. We focused on readmissions within 30 days of discharge, given this is the measure used in the HRRP, ${ }^{16}$ but conducted a sensitivity analysis of 14 days. Secondary outcomes included ED revisit within the 30 days. Given the data available, we only observed physician visits and hospitalizations that occurred within the Beth Israel Deaconess system.

\section{Analyses}

We conducted two analyses to assess whether the implementation of the postdischarge appointment service was associated with an increase in PCP follow-up and a decrease in the readmission rate.

In the first analysis, we focused only on hospitalizations from the medical and cardiology services during the postintervention period between January 2011 and September 2015 ( $\mathrm{n}=$ 17,582). We compared the PCP follow-up rate and the readmission rate among hospitalizations where the postdischarge appointment service was used versus those where it was not used. We used a multivariable logistic regression, and the covariates included in the model were age, gender, hospital length of stay, and diagnosis-related group (DRG) cost weight. The DRG cost weight captures the average resources used to treat Medicare patients' hospitalizations within a given DRG category and was used as a surrogate marker for the complexity of hospitalization. ${ }^{17}$ Instead of presenting odds ratios, we used predictive margins to generate adjusted percentage point estimates of the differences in our outcomes associated with the use of the postdischarge appointment service. ${ }^{18}$

In our second analysis, we examined the period before and after the introduction of the postdischarge appointment service (September 2008 through October 2015, n = 20,918). Among these hospitalizations, we conducted an instrumental variable analysis to address the concern that there are unmeasured differences between those patients who receive the discharge appointment service and those who do not. Instrumental variable analyses are used to estimate causal relationships in observational studies. ${ }^{19} \mathrm{~A}$ valid instrument is associated with the explanatory variable (use of the postdischarge appointment service) but has no independent effect on the outcomes (follow-up visits, readmissions). In this analysis, our set of instru- 


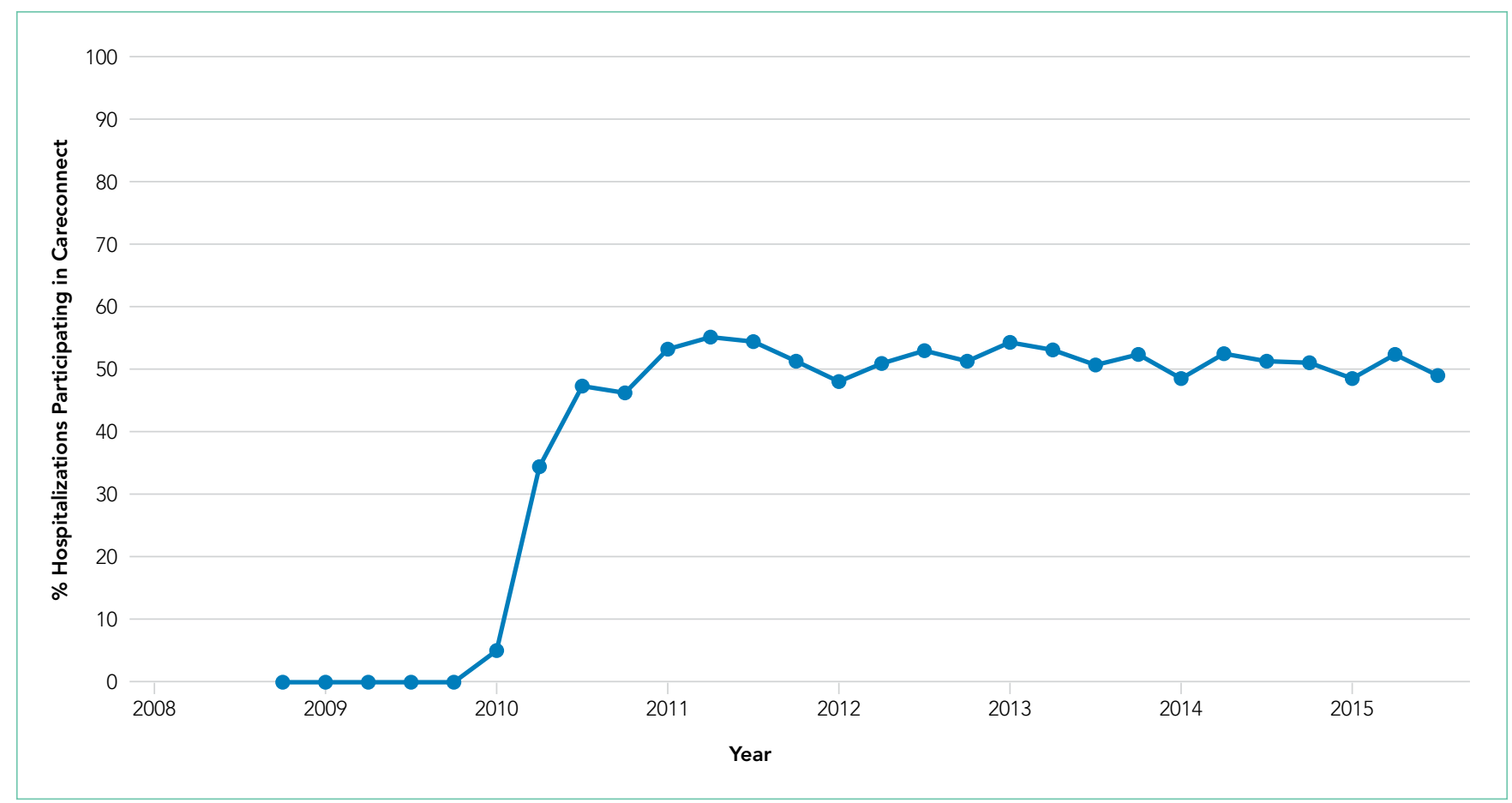

FIG. Fraction of Hospitalizations where the Postdischarge Appointment Service was Used Over Time

ments was the day of the week of admission (indicator variable for each day) interacted with the time period (pre- vs postintervention period).

This instrumental variable exploits the fact that the postdischarge appointment service was only available on weekdays and that physicians are asked to only submit the order for follow-up appointments on the day of discharge. We focused on the day of the week of admission (versus discharge) because of concerns that patients with more complicated hospital courses might be kept in the hospital over the weekend (eg, to facilitate testing available only on weekdays or to consult with regular physicians only available on weekdays). This would create a relationship between the day of discharge and the outcomes (follow-up visits, readmissions). The day of admission is less likely to be impacted by this bias. Given concerns that admissions on different days of the week might be different, our instrument is the day of the week interacted with the time period. Therefore, to create bias, there must be a systematic change in the nature of admissions on a given day of the week during this time period. We provide more details on this analysis, testing of the instrument, and results in the Appendix.

Analyses were conducted in Stata, version 14.2 (StataCorp LP, College Station, Texas). Statistical testing was two-sided, with a significance level of 0.05 , and the project was judged exempt by the Committee on Clinical Investigations for Beth Israel Deaconess Medical Center.

\section{RESULTS}

Overall, there were 17,582 hospitalizations on the medicine and cardiology services following implementation of the postdischarge appointment service. The use of the postdischarge ap- pointment service rose rapidly after it was introduced (Figure) and then plateaued at roughly $50 \%$. Of the hospitalizations where the postdischarge appointment service was used, the physician requested a new PCP for $1.2 \%$ of the patients. Among hospitalizations where the intervention was used, the average age was 65.5 years, $55.7 \%$ were female, the length of stay was 3.52 days, the DRG cost weight was 1.26 and $20.4 \%$ were patients on the cardiology service. Characteristics were similar in hospitalizations where the services were not used (Table 1).

\section{Multivariable Logistic Regression}

In this analysis, we focused on the 17,582 hospitalizations from January 2011 to September 2015 on the general medicine and cardiology services that occurred after the postdischarge appointment service was introduced. Among these hospitalizations, the postdischarge appointment service was used in $51.8 \%$ of discharges.

In an unadjusted analysis, patients discharged using the tool had higher rates of seven-day PCP follow-up (60.2\% vs $29.2 \%$, $P<.001)$ and lower 30 -day readmission rates (14.7\% vs $16.7 \%$; $P<.001$ ) than those who were not (Table 2). There was no significant difference in 30-day ED revisit between hospitalizations with and without use of the postdischarge appointment service $(22.3 \%$ vs $23.1 \%$; $P=.23)$.

This was echoed in our multivariable analysis where, controlling for other patient factors, use of the postdischarge appointment service was associated with an increased rate of follow-up with a PCP in seven days ( +31.9 percentage points; $95 \% \mathrm{Cl}: 30.2,33.6 ; P<.01)$ and a decreased likelihood of readmission within 30 days ( -3.8 percentage points; $95 \% \mathrm{Cl}:-5.2$, $-2.4 ; P<.01$ ) (Table 2). 
TABLE 1. Characteristics of Hospitalizations on the General Medicine and Cardiology Services after Intervention, Stratified by use of a Postdischarge Appointment Service (January 2011-September 2015; N = 17,582)

\begin{tabular}{|c|c|c|c|}
\hline Characteristic & $\begin{array}{c}\text { Postdischarge } \\
\text { Appointment Service Used } \\
(n=9,101)\end{array}$ & $\begin{array}{c}\text { Postdischarge } \\
\text { Appointment Service Not Used } \\
(n=8,481)\end{array}$ & $P$ Value \\
\hline $18-40 y$ & $8.0(732)$ & $7.7(649)$ & .04 \\
\hline $41-60 y$ & $30.1(2,739)$ & $28.6(2,426)$ & \\
\hline $61-80 y$ & $41.6(3,784)$ & $42.1(3,570)$ & \\
\hline \multicolumn{4}{|l|}{ Sex, $\%$} \\
\hline Female & $55.7(5,071)$ & $55.4(4,700)$ & .69 \\
\hline Male & $44.3(4,030)$ & $44.6(3,781)$ & \\
\hline Length of stay (mean days) (SD)* & $3.52(3.64)$ & $3.23(4.04)$ & $<.001$ \\
\hline General Medicine & $79.6(7,246)$ & $79.4(6,731)$ & \\
\hline
\end{tabular}

Abbreviations: DRG, diagnosis-related group; SD, standard deviation; $y$, years.

TABLE 2. Association between the Use of a Postdischarge Appointment Service and Outcomes in Multivariable Logistic Regression Analysis among Medicine and Cardiology Hospitalizations in the Postintervention Period (January 2011-September 2015; N = 17,582)

\begin{tabular}{|c|c|c|c|c|c|}
\hline \multirow[b]{2}{*}{ Outcome } & \multicolumn{3}{|c|}{ Unadjusted } & \multicolumn{2}{|c|}{ Multivariable Model ${ }^{a}$} \\
\hline & $\begin{array}{l}\text { Postdischarge Appointment } \\
\text { Service Used } \\
(\mathrm{n}=9,101)\end{array}$ & $\begin{array}{l}\text { No Use of Postdischarge } \\
\text { Appointment Service Intervention } \\
\qquad(n=8,481)\end{array}$ & $P$ Value & $\begin{array}{l}\text { Association in Percentage } \\
\text { Point Change } \\
(95 \% \mathrm{Cl})\end{array}$ & $P$ Value \\
\hline $\begin{array}{l}\text { Follow-up visit with a PCP within } 7 \text { days of } \\
\text { discharge, } \%\end{array}$ & 60.2 & 29.2 & $<.001$ & $\begin{array}{c}31.9 \\
(30.2,33.6)\end{array}$ & $<.001$ \\
\hline Readmission within 30 days of discharge, $\%$ & 14.7 & 16.7 & $<.001$ & $\begin{array}{c}-3.8 \\
(-5.2,-2.4)\end{array}$ & $<.001$ \\
\hline $\begin{array}{l}\text { Emergency department visit within } 30 \text { days } \\
\text { of discharge, } \%\end{array}$ & 22.3 & 23.1 & .23 & $\begin{array}{c}-1.6 \\
(-3.2,-0.04)\end{array}$ & .04 \\
\hline
\end{tabular}

aMultivariable logistic model covariates include age, gender, length of stay, and diagnosis-related group cost weight

Instrumental Variable Analysis

In our instrumental variable analysis, we used all hospitalizations both before and after the introduction of the intervention. In this analysis, we estimate that use of the postdischarge appointment service increases the probability of visiting a PCP within seven days by 33.4 percentage points (95\% Cl: $7.9 \%$, $58.9 \% ; P=.01$ ) (Table 3). The use of the postdischarge appointment was associated with a 2.5 percentage point $(95 \%$ $\mathrm{Cl}:-22.0 \%, 17.1 \% ; P=.80$ ) reduction in readmissions and a 4.8 percentage point $(95 \% \mathrm{Cl} ;-27.5 \%, 17.9 \% ; P=.68)$ reduction in an ED visit within 30 days (Table 3). Neither of these differences were statistically significant with wide confidence intervals.

In sensitivity analyses, we obtained similar results when we considered PCP visits and readmissions within 14 days.

\section{DISCUSSION}

The hospital introduced the postdischarge appointment service to facilitate postdischarge appointments and to deter 
TABLE 3. Impact of Postdischarge Appointment Service on Primary Care Physician Follow-up, Readmissions, and Emergency Department Visits Using Day of the Week of Admission as an Instrumental Variable (September 2008-October 2015; N = 20,918)

\begin{tabular}{|c|c|c|}
\hline Outcome & $\begin{array}{c}\text { Estimated Impact of Postdischarge Appointment Service, } \\
\text { Percentage Points } \\
(95 \% \mathrm{Cl})\end{array}$ & $P$ Value \\
\hline Readmission within 30 days of discharge, $\%$ & $-2.5(-22.0,17.0)$ & .80 \\
\hline Emergency department visit within 30 days of discharge, \% & $-4.8(-27.5,17.9)$ & .68 \\
\hline
\end{tabular}

readmissions. In our analyses the use of the postdischarge appointment service was associated with a substantial 30 percentage point increase in the likelihood of a PCP follow-up visit within seven days after hospital discharge. There was a roughly $2 \%$ reduction in 30 -day readmissions, but this difference was not consistently statistically significant across our analyses. Together, our evaluation implies that this type of intervention may make it much easier for patients to attend a PCP appointment, but scheduling an appointment alone may have a modest impact on deterring a readmission.

Our findings are inconsistent with prior studies that described a strong association between early PCP follow-up and readmissions. However, our results were consistent with research where follow-up visits were not clearly protective against readmissions. ${ }^{20}$ One potential explanation of the discrepant findings is that there are unmeasured socioeconomic differences between patients who have a PCP follow-up appointment and those who do not.

We advance the literature by studying an intervention focused only on increasing early PCP follow-up. Most successful readmission programs that have been studied in randomized, controlled trials take a multipronged approach, including transitional care management with dedicated staff and medication reconciliation. ${ }^{3-7,9,15,21-23}$ For example, Coleman and colleagues randomized 750 hospitalized patients to a care-transitions intervention, which led to a substantial decrease in readmissions. ${ }^{15}$ Their care-transitions intervention included four components: (1) timely PCP or specialist follow-up, (2) educating patients on how best to take their medications, (3) a patient-centered record that allowed them to track their own disease and care, and (4) disease-specific patient education. The relative importance of each of these components in deterring readmissions is unclear. Instead of this multipronged strategy, we focused on a single component-timely follow-up. Together, our study and these prior studies are broadly consistent with a meta-analysis that suggests that transitional care programs with a narrow focus are less successful at reducing readmissions. ${ }^{24}$ Facilitating early PCP follow-up alone is not a panacea and can be undermined by the incomplete or inexistent transmission of the discharge paperwork. ${ }^{25,} 26$ Moreover, the impact of interventions may only be seen among the highest-risk populations, and ongoing work by others seeks to identify these patients. ${ }^{27}$
Regardless of the impact on readmissions, it is important to acknowledge that early PCP follow-up offers many potential benefits. Continuing to evaluate and treat new diagnoses, adjusting and reconciling medications, reconnecting with outpatient providers, capturing new incidental findings, and ensuring stability through regular follow-up are just a few of the potential benefits. We believe the dramatic increase observed in PCP follow-up reflects the administrative complexity required for a patient to call their PCP's office and to schedule a follow-up appointment soon after they are discharged from the hospital. Our study implies that simply requesting that a patient call their PCP to schedule a timely appointment is often impossible, and this may be particularly true for those who need to obtain a new PCP.

Our study has many limitations. The study was limited to a single academic center, and the intervention was limited to patients cared for by the general medicine and cardiology services. Our multivariable regression analysis comparing outcomes among patients where the postdischarge appointment service was used and not used may be biased by unmeasured differences in these patients. We attempted to address this limitation by exploiting the fact that the intervention was only available on weekdays through an instrumental variable analysis, but the instrument we used itself is subject to bias. Also, in the instrumental variable analysis, our estimates were imprecise and therefore not powered to identify smaller but still clinically important reductions in readmissions. Given the data limitations, we could not compare the no-show rates among appointments made by the discharge appointment service versus those made by patients. Finally, we were only able to observe follow-up visits and hospitalizations within the health system, and it is possible that our results were biased by patients preferentially going to other hospitals for readmission.

In summary, we found that the introduction of a postdischarge appointment service resulted in substantially increased rates of early PCP follow-up but less clear benefits in preventing readmissions.

Disclosures: None of the authors have any conflicts of interest relevant to this work.

\section{References}

1. Boccutti C, Casillas G. Aiming for Fewer Hospital U-turns: The Medicare Hospital Readmission Reduction Program; March 10, 2017. https://www.kff.org/ 
medicare/issue-brief/aiming-for-fewer-hospital-u-turns-the-medicare-hospital-readmission-reduction-program. Accessed July 22, 2019

2. Centers for Medicare and Medicaid Services. FY 2017 IPPS Final Rule: Hospital Readmissions Reduction Program Supplemental Data File. https://www. cms.gov/Medicare/Medicare-Fee-for-Service-Payment/AcutelnpatientPPS/ Archived-Supplemental-Data-Files.html. Accessed June 22, 2019

3. Sharma G, Kuo YF, Freeman JL, Zhang DD, Goodwin JS. Outpatient follow-up visit and 30-day emergency department visit and readmission in patients hospitalized for chronic obstructive pulmonary disease. Arch Intern Med. 2010;170(18):1664-1670. https://doi.org/10.1001/archinternmed.2010.345.

4. Rennke S, Nguyen OK, Shoeb MH, et al. Hospital-initiated transitional care interventions as a patient safety strategy: a systematic review. Ann Intern Med. 2013;158(5 Pt 2):433-440. https://doi.org/10.7326/0003-4819-158-5 201303051-00011.

5. Misky GJ, Wald HL, Coleman EA. Post hospitalization transitions: examining the effects of timing of primary care provider follow-up. J Hosp Med. 2010;5(7):392-397. https://doi.org/10.1002/jhm.666.

6. Hesselink G, Schoonhoven L, Barach $P$, et al. Improving patient handovers from hospital to primary care: a systematic review. Ann Intern Med. 2012;157(6):417428. https://doi.org/10.7326/0003-4819-157-6-201209180-00006.

7. Hernandez AF, Greiner MA, Fonarow GC, et al. Relationship between early physician follow-up and 30-day readmission among Medicare beneficiaries hospitalized for heart failure. JAMA. 2010;303(17):1716-1722. https://doi. org/10.1001/jama.2010.533

8. Muus KJ, Knudson A, Klug MG, et al. Effect of post discharge follow-up care on re-admissions among US veterans with congestive heart failure: a rural-urban comparison. Rural Remote Health. 2010;10(2):1447.

9. Brooke BS, Stone DH, Cronenwett JL, et al. Early primary care provider follow-up and readmission after high-risk surgery. JAMA Surg. 2014;149(8):821 828. https://doi.org/10.1001/jamasurg.2014.157.

10. Leschke J, Panepinto JA, Nimmer M, et al. Outpatient follow-up and rehospitalizations for sickle cell disease patients. Pediatr Blood Cancer. 2012;58(3):406-409. https://doi.org/10.1002/pbc.23140.

11. Field TS, Ogarek J, Garber L, Reed G, Gurwitz JH. Association of early post discharge follow-up by a primary care physician and 30-day rehospitalization among older adults. J Gen Intern Med. 2015;30(5):565-571. https://doi. org/10.1007/s11606-014-3106-4.

12. Kashiwagi DT, Burton MC, Kirkland LL, Cha S, Varkey P. Do timely outpatient follow-up visits decrease hospital readmission rates? Am J Med Qual. 2012;27(1):11-15. https://doi.org/10.1177/1062860611409197.

13. Hansen LO, Young RS, Hinami K, Leung A, Williams MV. Interventions to reduce 30-day rehospitalization: a systematic review. Ann Intern Med. 2011;155(8):520-528. https://doi.org/10.7326/0003-4819-155-8-20111018000008

14. Ryan J, Kang S, Dolacky S, Ingrassia J, Ganeshan R. Change in readmissions and follow-up visits as part of a heart failure readmission quality improvement initiative. Am J Med. 2013;126(11):989-994.e1. https://doi.org/10.1016/j.amjmed.2013.06.027

15. Coleman EA, Parry C, Chalmers S, Min SJ. The care transitions intervention: results of a randomized controlled trial. Arch Intern Med. 2006;166(17):18221828. https://doi.org/10.1001/archinte.166.17.1822.

16. Thomas JW. Should episode-based economic profiles be risk adjusted to account for differences in patients' health risks? Health Serv Res. 2006;41(2):581598. https://doi.org/10.1111/j.1475-6773.2005.00499.x.

17. Mendez CM, Harrington DW, Christenson P, Spellberg B. Impact of hospital variables on case mix index as a marker of disease severity. Popul Health Manag. 2014;17(1):28-34. https://doi.org/10.1089/pop.2013.0002.

18. Muller CJ, MacLehose RF. Estimating predicted probabilities from logistic regression: different methods correspond to different target populations. Int J Epidemiol. 2014;43(3):962-970. https://doi.org/10.1093/ije/dyu029.

19. Angrist JD, Krueger AB. Instrumental variables and the search for identification: From supply and demand to natural experiments. J Econ Perspect. 2001;15(4):69-85. https://doi.org/10.1257/jep.15.4.69.

20. Dimick JB, Ryan AM. Methods for evaluating changes in health care policy: the difference-in-differences approach. JAMA. 2014;312(22):2401-2402. https://doi.org/10.1001/jama.2014.16153.

21. Peikes D, Chen A, Schore J, Brown R. Effects of care coordination on hospitalization, quality of care, and health care expenditures among Medicare beneficiaries: 15 randomized trials. JAMA. 2009;301(6):603-618. https://doi. org/10.1001/jama.2009.126.

22. Jack BW, Chetty VK, Anthony D, et al. A reengineered hospital discharge program to decrease rehospitalization: a randomized trial. Ann Intern Med. 2009;150(3):178-187. https://doi.org/10.7326/0003-4819-150-3-20090203000007.

23. Naylor MD, Brooten DA, Campbell RL, et al. Transitional care of older adults hospitalized with heart failure: a randomized, controlled trial. J Am Geriatr Soc. 2004;52(5):675-684. https://doi.org/10.1111/j.1532-5415.2004.52202.x.

24. Leppin AL, Gionfriddo MR, Kessler M, et al. Preventing 30-day hospital readmissions: a systematic review and meta-analysis of randomized trials. JAMA Intern Med. 2014;174(7):1095-1107. https://doi.org/10.1001/jamainternmed.2014.1608.

25. Kripalani S, LeFevre F, Phillips CO, et al. Deficits in communication and information transfer between hospital-based and primary care physicians: implications for patient safety and continuity of care. JAMA. 2007;297(8):831-841. https://doi.org/10.1001/jama.297.8.831.

26. van Walraven $C$, Seth $R$, Austin PC, Laupacis A. Effect of discharge summary availability during post discharge visits on hospital readmission. J Gen Intern Med. 2002;17(3):186-192. https://doi.org/10.1046/j.1525-1497.2002.10741.x.

27. Hoyer EH, Brotman DJ, Apfel A, et al. Improving outcomes after hospitalization: A prospective observational multicenter evaluation of care coordination strategies for reducing 30-day readmissions to Maryland Hospitals. J Gen Intern Med. 2018;33(5):621-627. https://doi.org/10.1007/s11606-017-4218-4 